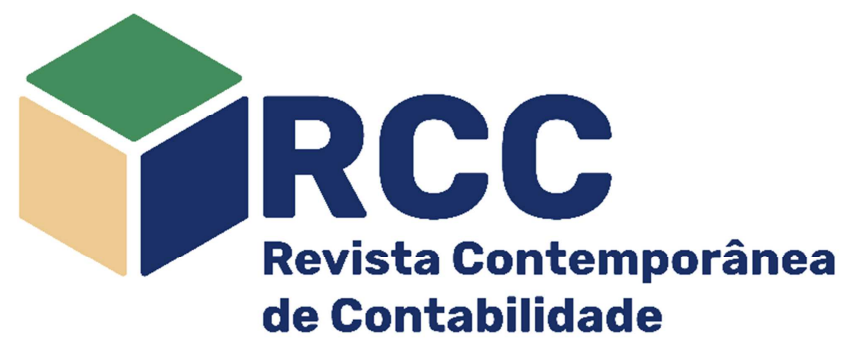

\title{
Desempenho econômico-financeiro e as decisões de instauração de regimes especiais no setor de saúde suplementar brasileiro
}

\author{
Financial performance and the decisions to establish special regimes in the Brazilian supplementary \\ health sector
}

\section{Desempeño económico-financiero y decisiones para establecer regímenes especiales en el sector complementario de salud brasileño}

\author{
Tatiele Alves Reis* \\ Mestre em Ciências Contábeis (UFRJ) \\ Professora Substituta do Departamento de Ciências \\ Contábeis e Finanças (UFRRJ), Seropédica/RJ, Brasil \\ tatiele.reis@hotmail.com \\ https://orcid.org/0000-0003-3384-8182
}

\author{
Marcelo Alvaro da Silva Macedo \\ Doutor em Engenharia de Produção (UFRJ) \\ Professor do Programa de Pós-Graduação em Ciências Contábeis \\ (UFRJ), Rio de Janeiro/RJ, Brasil \\ malvaro.facc.ufrj@gmail.com \\ http://orcid.org/0000-0003-2071-8661
}

José Augusto Veiga da Costa Marques Pós-Doutor em Controladoria e Contabilidade na Universidade de São Paulo (USP) Professor do Programa de Pós-Graduação em Ciências Contábeis (UFRJ), Rio de Janeiro/RJ, Brasil joselaura@uol.com.br https://orcid.org/0000-0002-8673-961X

Endereço do contato principal para correspondência* BR-465, Km 7 - ICSA/UFRRJ - Seropédica, CEP. 23.897-000 - Seropédica/RJ, Brasil

\section{Resumo}

Este estudo teve como objetivo analisar quais indicadores econômico-financeiros são capazes de explicar a decisão da ANS de instaurar regimes especiais nas operadoras, considerando as instaurações de regimes especiais ocorridas de 2017 a 2019. Foi utilizada a regressão logística com uma amostra de 154 operadoras. Após a análise fatorial, foi estabelecido como variáveis independentes: três fatores (rentabilidade, liquidez, despesas) e quatro indicadores (margem EBITDA, endividamento, despesa médica e ciclo financeiro). A regressão logística utilizou o processo de reamostragem em t-1 e t-2. As variáveis relacionadas com a instauração de regimes especiais foram: o fator liquidez e os indicadores endividamento e ciclo financeiro; o último relacionado de forma mais fraca. Concluiu-se que a situação econômicofinanceira é relevante na determinação dos regimes especiais de direção fiscal e técnica, principalmente a liquidez e o endividamento. Espera-se que este resultado contribua para uma melhor gestão das operadoras, a partir do controle desses aspectos financeiros.

Palavras-Chave: Indicadores financeiros; Operadoras de planos de saúde; Regimes especiais

\section{Abstract}

This research analyzes financial ratios that explain the Brazilian National Supplementary Health Agency's (ANS) decision to intervene in private health plan operators' administration based on interventions that occurred from 2017 to 2019. Logistic regression was used with a sample of 154 operators. After factor analysis, the following independent variables were established: three factors (profitability, liquidity, expenses) and four indicators (EBITDA margin, indebtedness, medical expenses, and financial cycle). The logistic regression used a resampling process at $\mathrm{t}-1$ and $\mathrm{t}-2$. Variables related to the ANS intervention by introducing special regimes were: the factor liquidity and the indicators indebtedness and financial cycle (the latter presented a weak relation). The results show that the health plan operators' financial condition, particularly regarding liquidity and indebtedness, is relevant to the ANS's decision to introduce fiscal and technical special regimes. These findings can contribute to better management of private health operators, offering evidence of the importance of controlling these financial aspects.

Keywords: Financial ratios; Health plan operators; Special regimes 


\section{Resumen}

Este estudio tuvo como objetivo analizar qué índices financieros son capaces de explicar la decisión de la ANS de establecer regímenes especiales en los operadores, considerando el establecimiento de regímenes especiales ocurridos de 2017 a 2019. Se utilizó regresión logística con una muestra de 154 operadores. Después del análisis de factores, se estableció como variables independientes: tres factores (rentabilidad, liquidez y gastos) y cuatro indicadores (margen EBITDA, endeudamiento, gastos médicos y ciclo financiero). La regresión logística utilizó el proceso de remuestreo en t-1 y t-2. Las variables relacionadas con el establecimiento de regímenes especiales fueron: el factor de liquidez y los indicadores de deuda y ciclo financiero; este último débilmente relacionado. Se concluyó que la situación financiera es pertinente en la determinación de regímenes especiales (fiscal y técnica), especialmente la liquidez y el endeudamiento. Se espera que este resultado contribuya a una mejor gestión de los operadores, desde el control de estos aspectos financieros.

Palabras clave: Indicadores financieros; Operadores de planes de salud; Regímenes especiales

\section{Introdução}

O setor de saúde suplementar é bastante relevante para a sociedade e, também para a economia. Segundo estudos divulgados pela Federação Nacional de Saúde Suplementar - Fenasaúde, o mercado de saúde suplementar empregava aproximadamente $8,1 \%$ da força de trabalho brasileira em julho de 2018 (Fenasaúde, 2018) e movimentou $\mathrm{R} \$ 200$ bilhões em 2018 - o que corresponde a aproximadamente $3 \%$ do PIB nacional (Fenasaúde, 2019). Segundo dados coletados no sítio da Agência Nacional de Saúde Suplementar - ANS (www.ans.gov.br, recuperado em 19 de março, 2021), em janeiro de 2021, o setor contava com 1.184 operadoras ativas, considerando todas as modalidades; e, em dezembro de 2020 , possuía 47,6 milhões de beneficiários em planos de assistência médica com ou sem odontologia e 27 milhões em planos exclusivamente odontológicos.

Os indicadores econômico-financeiros são usados para avaliar a capacidade de uma empresa em pagar suas dívidas, obter sucesso comercial e gerencial e, até mesmo, para a regulamentação estatutária do desempenho de uma empresa (Barnes,1987). Além disso, é possível encontrar diversas pesquisas em que os indicadores econômico-financeiros são empregados para predizer a insolvência nas organizações. Neste campo, podem-se citar os estudos clássicos de Beaver (1966) e Altman (1968); como os mais recentes de Guimarães e Alves (2009), Zhen-Jia-Liu (2014), Scalzer, Rodrigues e Macedo (2015).

Como ressaltado por Nogueira (2004), a garantia de continuidade da prestação de serviços de assistência à saúde está vinculada à situação econômico-financeira das operadoras, principalmente ao aspecto de solvência. Desta forma, pode-se dizer que a solvência é condição necessária para o bom funcionamento do setor de saúde suplementar.

Desde a Lei 9.656 (1998) e Lei no 9.961 (2000), demonstrava-se relevante a manutenção do equilíbrio econômico-financeiro das operadoras, como também, a instituição de regimes especiais já era prevista. As operadoras são periodicamente analisadas com o objetivo de verificar o equilíbrio financeiro e a qualidade na prestação de serviços de assistência à saúde. Uma vez identificada uma anormalidade (assistencial, financeira ou administrativa), a operadora pode ser requerida a elaborar um plano com as medidas necessárias para a correção da falha. Caso a operadora não cumpra com as medidas corretivas, poderá ser submetida aos regimes especiais que podem ser de três tipos: direção técnica, direção fiscal ou liquidação extrajudicial. Considera-se, portanto, que os regimes especiais são intervenções realizadas pela ANS diante de uma anormalidade grave que coloca em risco a assistência prestada aos beneficiários, a continuidade ou a qualidade do atendimento à saúde - como disposto pelas Resoluções Normativas no 316 (ANS, 2012a) e no 417 (ANS, 2016b).

Trabalhos anteriores como os de Jesus, Queiroz, Macedo, Cruz, e Sauerbronn (2019) e Guzella e Rodrigues (2015) encontraram evidências de que os indicadores econômico-financeiros são capazes de predizer o desempenho operacional em período futuro. Embora a análise de desempenho envolvendo indicadores financeiros e não financeiros seja prática comum, o estudo de Sancovschi, Macedo e Silva (2014) demonstrou que a perspectiva econômico-financeira das operadoras de saúde tem maior influência sobre a decisão de instauração dos regimes especiais.

Considerando a relevância deste mercado para a sociedade e economia, bem como todas as complexidades oriundas da natureza do negócio, pode-se dizer que a regulação do setor é importante. E tal regulação deve contemplar um rigoroso acompanhamento econômico-financeiro das operadoras de saúde, uma vez que a vulnerabilidade financeira destas constitui um risco à prestação de serviços de saúde aos beneficiários e à economia do país.

Portanto, considerando que os índices econômico-financeiros são relevantes para a análise do setor de saúde suplementar e que a instauração dos regimes especiais pode estar relacionada com um baixo desempenho econômico-financeiro das operadoras, tem-se a seguinte questão de pesquisa: Quais indicadores econômico-financeiros são capazes de explicar a decisão da ANS de instaurar regimes especiais nas operadoras? 
Assim, o estudo tem como objetivo analisar quais indicadores econômico-financeiros são capazes de explicar a decisão da ANS de instaurar regimes especiais nas operadoras, considerando os indicadores econômico-financeiros do período de 2015 a 2019 e as instaurações de regimes especiais ocorridas de 2017 a 2019.

Sendo assim, o estudo avança no sentido de promover maior conhecimento sobre análise de desempenho, principalmente na gestão financeira das operadoras de planos de saúde. Espera-se que a partir da determinação de quais indicadores financeiros estão relacionados com a instauração de regimes especiais, as operadoras possam priorizar o controle desses aspectos financeiros, evitando a ocorrência de anormalidades graves e a consequente instauração de regimes especiais.

\section{Referencial Teórico}

Esta seção está dividida em quatro subseções: análise de desempenho organizacional, análise do desempenho econômico-financeiro no setor de saúde suplementar, pesquisas sobre análise de desempenho econômico-financeiro do setor de saúde suplementar e hipótese de pesquisa. A busca das pesquisas foi feita por meio dos periódicos Capes e Google Acadêmico, a partir dos termos "desempenho organizacional", "indicadores financeiros", "saúde suplementar", "regimes especiais" e "operadoras de planos de saúde". Quanto às normas pertinentes ao setor, estas foram retiradas do sítio da ANS (www.ans.gov.br).

\subsection{Análise de desempenho organizacional}

Como exposto por Barnes (1987), os indicadores financeiros são usados para avaliar a capacidade de uma empresa em pagar suas dívidas, obter o sucesso comercial e gerencial e, também para a regulamentação estatutária do desempenho de uma empresa. No entanto, o autor demonstra que os índices financeiros costumam ser utilizados como insumo em modelos estatísticos com o objetivo de predizer, por exemplo, falhas corporativas, classificação de crédito, avaliação de risco e para testar hipóteses econômicas.

De acordo com Altman (1968), os indicadores econômico-financeiros considerados como mais significativos são os que medem lucratividade, liquidez e solvência. A partir dos indicadores financeiros, as demonstrações contábeis são transformadas em informações mais fáceis de serem visualizadas, permitindo que se conclua sobre questões relativas à concessão de crédito, assertividade administrativa, solvência, lucratividade, eficiência e continuidade da organização (Matarazzo, 2010).

No entanto, autores como Kaplan e Norton (1992) e Bhimani e Langfield-Smith (2007), destacam que a avaliação de desempenho deve considerar também os aspectos operacionais, e, portanto, devem-se utilizar indicadores financeiros e não financeiros. Bhimani e Langfield-Smith (2007) afirmam que informações não financeiras são necessárias para capturar a relevância das decisões estratégicas. Kaplan e Norton (1992) desenvolveram o BSC - uma ferramenta que avalia a empresa em quatro diferentes perspectivas: cliente, negócios internos, inovação e aprendizagem e, financeira.

\subsection{Análise do desempenho econômico-financeiro no setor de saúde suplementar}

A Lei no 9.961 (2000) afirma que a ANS tem por finalidade promover a defesa do interesse público por meio da regulação das operadoras do setor de saúde suplementar, contribuindo, assim, para o desenvolvimento das ações de saúde no país. Entre as atribuições da ANS, destaca-se, no âmbito desta pesquisa, o acompanhamento dos indicadores econômico-financeiros e as intervenções realizadas pela ANS nas operadoras.

De acordo com Soares, Thóphilo e Corrar (2009), entre as medidas adotadas pela Diretoria de Normas e Habilitação das Operadoras (DIOPE), estão a instituição do Plano de Contas Padrão (PCP) e o reporte das informações contábeis trimestrais à ANS por meio do Documento de Informações Periódicas (DIOPS), sendo por meio dessas informações que a ANS monitora e controla a situação econômicofinanceira das operadoras.

Dentro da perspectiva dos indicadores de desempenho mencionados na legislação, é importante citar a criação do Programa de Qualificação de Operadoras em 2004, tendo este passado por uma reestruturação em 2015. Neste programa é realizada a avaliação de desempenho das operadoras, a qual é expressa por meio do Índice de Desempenho em Saúde Suplemementar - IDSS (www.ans.gov.br, recuperado em 29 de março, 2019).

O IDSS é calculado a partir de um conjunto de indicadores definidos pela ANS e constantemente avaliados para o aprimoramento do Programa de Qualificação das Operadoras, e as dimensões que compõem atualmente o IDSS são: qualidade em atenção à saúde, garantia de acesso, sustentabilidade no mercado e gestão de processos e regulação (ANS, 2015). De acordo com Oliveira e Kornis (2017), estas novas dimensões são resultado do alinhamento aos eixos direcionais da ANS, à agenda regulatória e à literatura de qualidade em saúde. 
Os indicadores econômico-financeiros estão presentes no IDSS na dimensão sustentabilidade no mercado. Esta dimensão diz respeito ao equilíbrio econômico-financeiro das operadoras, avaliando a capacidade delas ficarem em dia com suas obrigações financeiras junto a seus prestadores para 0 atendimento com padrão adequado de qualidade e de forma continua a seus beneficiários (ANS, 2017b).

Além disso, conforme disposto na Resolução Normativa (RN) ํo 400/2016, a ANS realiza a análise técnica individual de acompanhamento econômico-financeiro por intermédio da Nota Técnica de Acompanhamento Econômico-Financeiro (NTAEF), nas operadoras que, a partir da DIOPS e dos documentos que compõem o conjunto das Demonstrações Contábeis e dos Relatórios de Auditoria Independente, não atendem aos critérios de risco e relevância definidos (ANS, 2016a).

A respeito da análise de desempenho das operadoras, pode-se observar que a ANS possui avaliações baseadas em dois grupos de indicadores: financeiros e não financeiros. De um lado, encontra-se - IDSS que é composto por um mix de indicadores financeiros e não financeiros e, do outro lado, a utilização de ferramentas de avaliação exclusivamente econômico-financeiras para o acompanhamento do desempenho das operadoras.

Quando identificada uma anormalidade assistencial, a operadora pode ser requerida a elaborar o Plano de Recuperação Assistencial (PRASS) (ANS, 2016b). Enquanto no caso de uma anormalidade econômico-financeira, a operadora deve adotar os Procedimentos de Adequação Econômico-Financeira (PAEF), ficando obrigada a elaborar o Plano de Adequação Econômico-Financeira (PLAEF) ou aderir ao Termo de Assunção de Obrigações Econômico-Financeiras (TAOEF), dependendo dos critérios de risco e relevância, conforme apontamento a ser feito na NTAEF (ANS, 2012b). Caso a operadora não cumpra com as medidas corretivas dos planos, poderá ser submetida aos regimes especiais que podem ser de três tipos: direção técnica, direção fiscal ou liquidação extrajudicial como disposto pelas RN no 316 (ANS, 2012a) e № 417 (ANS, 2016b).O regime especial de direção técnica pode ser decretado quando forem identificadas anormalidades administrativas graves de natureza assistencial que colocam em risco a assistência prestada aos beneficiários de uma operadora (ANS, 2016b). Na direção fiscal, a instauração ocorre a partir da identificação de uma ou mais anormalidades econômico-financeiras ou administrativas graves que colocam em risco a continuidade ou a qualidade do atendimento à saúde (ANS, 2012a).

O regime especial de liquidação extrajudicial pode ser estabelecido diante da ocorrência de pelo menos uma das seguintes situações: indícios de dissolução irregular; não alcance dos objetivos de saneamento das anormalidades econômico-financeiras ou administrativas graves; ausência de substituição de administradores inabilitados ou afastados por determinação da ANS, sempre que importar em risco para a continuidade ou a qualidade do atendimento à saúde dos beneficiários; aplicação de sanção administrativa de cancelamento de sua autorização de funcionamento ou do registro provisório; e violação grave pela administração da operadora de normas legais e estatutárias que disciplinam a atividade da instituição, bem como das determinações da ANS (ANS, 2012a).

Como citado anteriormente, a ANS utiliza indicadores financeiros e não financeiros para a análise das operadoras de saúde, o que é evidenciado por meio das dimensões que compõem o IDSS. Essa visão de que a análise de desempenho deve contemplar aspectos financeiros e operacionais é defendida por autores como Bhimani e Langfield-Smith (2007) e Kaplan e Norton (1992). No entanto, embora a análise de desempenho envolvendo as perspectivas financeira e não financeira seja prática comum, existem estudos empíricos que indicam que os indicadores econômico-financeiros podem prevalecer na análise de desempenho.

Jesus et al.(2019) e Guzella e Rodrigues (2015) encontraram evidências de que os indicadores econômico-financeiros são capazes de predizer o desempenho operacional em período futuro. Enquanto o estudo de Sancovschi et al.(2014) achou que as intervenções realizadas pela ANS nas operadoras de saúde em 2009 estavam significativamente relacionadas às dimensões econômica e financeira e de estrutura e operação em 2007, e somente à dimensão econômica e financeira em 2008. Logo, a perspectiva econômico-financeira demonstrou ter maior influência sobre a decisão de instauração dos regimes especiais pela ANS, podendo prever sua ocorrência com até dois anos de antecedência.

Segundo informações coletadas no sítio da ANS (www.ans.gov.br, recuperado em 28 de maio, 2019), a ANS divulga anualmente o Anuário, um periódico que apresenta os principais dados contábeis de cada uma das operadoras e seus indicadores econômico-financeiros. Tal periódico representa um incentivo a excelência gerencial e colabora para a incorporação de boas práticas de governança e maior transparência do setor. O Anuário é composto por um total de 19 indicadores que foram classificados em diferentes subgrupos de acordo com a finalidade, seguindo as orientações de Matarazzo (2010), na Figura 1.

\subsection{Pesquisas sobre análise de desempenho econômico-financeiro do setor de saúde suplementar}

Soares et al. (2009) buscaram verificar se os indicadores econômico-financeiros utilizados pela ANS são os mais relevantes para classificar e avaliar o desempenho econômico-financeiro das operadoras de saúde, se baseando nos indicadores tradicionais apontados pela literatura. Os autores encontraram que a aplicação da técnica de análise fatorial no grupo de indicadores tradicionais e no grupo de indicadores 
utilizados pela ANS resultou no mesmo resultado, sendo os indicadores Participação de Capitais de Terceiros, Imobilização do Patrimônio Líquido, Liquidez Corrente, Liquidez Geral e Rentabilidade do Patrimônio Líquido, os mais relevantes para avaliar o desempenho das operadoras. Diante disso, concluíram que a ANS utiliza os indicadores mais relevantes na formação de seu indicador de qualificação.

\begin{tabular}{|c|c|c|c|c|}
\hline Grupo & Finalidade & Indicador & Sigla & Fórmula \\
\hline \multirow{3}{*}{$\begin{array}{l}\text { Estrutura de } \\
\text { Capital }\end{array}$} & \multirow{3}{*}{$\begin{array}{l}\text { Identificar a composição e a } \\
\text { estrutura de financiamento. }\end{array}$} & $\begin{array}{l}\text { Imobilização do Ativo } \\
\text { Total }\end{array}$ & IMOB & Ativo Não Circulante / Ativo Total \\
\hline & & Endividamento & ENDIV & $\begin{array}{l}\text { (Passivo Circulante + Passivo Não Circulante) / } \\
\text { Ativo Total }\end{array}$ \\
\hline & & $\begin{array}{l}\begin{array}{l}\text { Composição } \\
\text { endividamento }\end{array} \\
\end{array}$ & CE & $\begin{array}{l}\text { Passivo Circulante / (Passivo Circulante + } \\
\text { Passivo Não Circulante) }\end{array}$ \\
\hline \multirow{6}{*}{ Rentabilidade } & \multirow{6}{*}{$\begin{array}{l}\text { Verificar a capacidade da } \\
\text { operadora em gerar retornos. }\end{array}$} & $\begin{array}{l}\text { Retorno sobre } 0 \\
\text { Ativo Total }\end{array}$ & ROA & Resultado Líquido / Ativo Total \\
\hline & & $\begin{array}{l}\text { Retorno sobre }{ }^{\circ} \\
\text { Patrimônio Líquido* }^{\circ}\end{array}$ & ROE & Resultado Líquido / Patrimônio Líquido \\
\hline & & $\begin{array}{l}\text { Margem de Lucro } \\
\text { Bruto }\end{array}$ & MLB & Resultado Bruto / Contraprestações Efetivas \\
\hline & & $\begin{array}{l}\text { Margem de Lucro } \\
\text { Líquido }\end{array}$ & MLL & Resultado Líquido / Contraprestações Efetivas \\
\hline & & $\begin{array}{l}\text { Margem } \\
\text { (LAJIR) }\end{array}$ & EBIT & $\begin{array}{l}\text { (Resultado Líquido + Despesas Financeiras + } \\
\text { IR + CSLL - Impostos Diferidos) / } \\
\text { Contraprestações Efetivas }\end{array}$ \\
\hline & & $\begin{array}{l}\text { Margem } \\
(\text { LAJIDA) }\end{array}$ & EBITDA & $\begin{array}{l}\text { (Resultado Líquido + Despesas Financeiras + } \\
\text { IR + CSLL - Impostos Diferidos + Depreciação } \\
+ \text { Amortização) / Contraprestações Efetivas }\end{array}$ \\
\hline \multirow[t]{2}{*}{ Liquidez } & \multirow{2}{*}{$\begin{array}{l}\text { Avaliar a capacidade de } \\
\text { pagamento das dívidas. }\end{array}$} & Liquidez Geral & LG & $\begin{array}{l}\text { (Ativo Circulante + Realizável a Longo Prazo) / } \\
\text { (Passivo Circulante + Passivo Não Circulante) }\end{array}$ \\
\hline & & Liquidez Corrente & LC & Ativo Circulante / Passivo Circulante \\
\hline \multirow{5}{*}{ Despesas } & \multirow{5}{*}{$\begin{array}{l}\text { Verificar a relação das } \\
\text { despesas com as receitas } \\
\text { com operação de planos de } \\
\text { saúde. }\end{array}$} & $\begin{array}{l}\text { İndice Despesas } \\
\text { Médicas } \\
\text { (sinistralidade) }\end{array}$ & DM & $\begin{array}{l}\text { Eventos Indenizáveis } \\
\text { Contraprestações Efetivas }\end{array}$ \\
\hline & & $\begin{array}{l}\text { Îndice de Despesas } \\
\text { de Comercialização }\end{array}$ & DC & $\begin{array}{l}\text { Despesas de Comercialização } \\
\text { Contraprestações Efetivas }\end{array}$ \\
\hline & & $\begin{array}{l}\text { Índice de Despesas } \\
\text { Administrativas }\end{array}$ & DA & $\begin{array}{l}\text { Despesas Administrativas / Contraprestações } \\
\text { Efetivas }\end{array}$ \\
\hline & & Índice Combinado & COMB & $\begin{array}{l}\text { (Despesas Administrativas }+ \text { Despesas de } \\
\text { Comercialização }+ \text { Eventos Indenizáveis } \\
\text { Líquidos) / Contraprestações Efetivas }\end{array}$ \\
\hline & & $\begin{array}{l}\text { Índice Combinado } \\
\text { Ampliado }\end{array}$ & COMBA & $\begin{array}{l}\text { (Despesas Administrativas + } \\
\text { Comercialização }+ \text { Evespesas de } \\
\text { Líquidos) / (Contraprestações } \\
\text { Resultado Financeiro Líquido) }\end{array}$ \\
\hline \multirow{2}{*}{ Atividade } & \multirow{2}{*}{$\begin{array}{l}\text { Identificar quanto tempo leva } \\
\text { para receber as vendas e } \\
\text { pagar os } \text { eventos } \\
\text { assistenciais }\end{array}$} & $\begin{array}{ll}\text { Prazo Médio ro de } \\
\text { Contraprestações a } \\
\text { Receber }\end{array}$ & PMCR & $\begin{array}{l}\text { (Créditos Operadoras de } \\
\text { Contraprestações Efetivas) } \times 360\end{array}$ \\
\hline & & $\begin{array}{ll}\text { Prazo Médio } & \text { de } \\
\text { Pagamento } & \text { de } \\
\text { Eventos } & \\
\end{array}$ & PMPE & $\begin{array}{l}\text { (Eventos a Liquidar / Eventos Indenizáveis } \\
\text { Líquidos) } \times 360\end{array}$ \\
\hline Vendas & $\begin{array}{l}\text { Analisar a receita com } \\
\text { operação de planos de saúde } \\
\text { gerada por beneficiário. }\end{array}$ & $\begin{array}{l}\text { Tíquete } \\
\text { Mensal }\end{array}$ & TM & $\begin{array}{l}\text { Contraprestações } \\
\text { Beneficiários x 12) }\end{array}$ \\
\hline
\end{tabular}

Figura 1 - Indicadores econômico-financeiros presentes no Anuário ANS

*Não cabe interpretação deste indicador caso a operadora apresente Patrimônio Líquido negativo.

Fonte: Elaborado pelos autores com base em Matarazzo (2010) e ANS (2019a, 2018a, 2017a, 2016c)

Veloso e Malik (2010) tinham como propósito avaliar o desempenho econômico-financeiro de empresas da área de saúde, principalmente os hospitais, comparando o desempenho destes com as operadoras de planos de saúde e as empresas em geral. Os autores não conseguiram rejeitar a hipótese de que não existem diferenças em termos de rentabilidade entre hospitais, operadoras e empresas em geral. No entanto, verificaram que quanto maior as empresas, maior a dificuldade para rejeitar essa hipótese. Portanto, o tamanho da receita das empresas é um fator com influência na rentabilidade das empresas analisadas.

Já Kudlawicz (2013) estudou quais as características que diferenciam as operadoras de planos de saúde com rentabilidade maior das de rentabilidade menor. Por meio dos resultados obtidos pela aplicação do modelo de dados em painel, a autora concluiu que não há muitas diferenças entre as operadoras com rentabilidade maior e aquelas com rentabilidade menor. No entanto, concluiu também que aquelas que possuem maior rentabilidade focam suas origens em recursos próprios e as empresas com menor rentabilidade buscam seus recursos em terceiros e no curto prazo.

Kudlawicz e Santos (2013) tiveram como objetivo identificar o perfil financeiro das operadoras de planos de saúde, a partir dos indicadores presentes na literatura. Com o uso da técnica de análise fatorial, 
os autores concluíram que os indicadores do fator Rentabilidade são os que mais importam para o setor de saúde suplementar.

O estudo de Sancovschi et al. (2014) verificou a relação existente entre a pontuação obtida pelas operadoras nas dimensões do IDSS e a decisão de intervenção nas operadoras por parte da ANS. No período deste estudo, o IDSS ainda não havia sido reformulado e era composto pelas seguintes dimensões: atenção à saúde (IDAS), econômico-financeira (IDEF), estrutura e operação (IDEO) e satisfação dos beneficiários (IDSB). Foi encontrado que as intervenções realizadas pela ANS nas operadoras de saúde em 2009 estavam significativamente relacionadas às dimensões IDEF (negativamente) e IDEO (positivamente) em 2007, e apenas à IDEF (negativamente) em 2008. A partir destes resultados, Sancovschi et al. (2014) concluíram que o desempenho das operadoras na dimensão econômico-financeira do IDSS é capaz de explicar boa parte das intervenções realizadas pela ANS em 2009.

Silva e Loebel (2017) realizaram um estudo com objetivo de identificar o desempenho econômicofinanceiro de operadoras de planos privados de saúde e comparar seus resultados entre os anos de 2008 e 2012. Os autores encontraram por meio da estatística descritiva dos índices que o desempenho econômicofinanceiro foi assimétrico ao longo dos anos de análise, apresentando diferenças entre os valores das médias e das medianas de cada um dos índices calculados. Além disso, por meio do teste de mediana, Silva e Loebel (2017) concluíram que apenas os índices Retorno sobre o Ativo Total, Endividamento de Curto Prazo e Sinistralidade obtiveram diferenças significativas entre os valores médios, quando comparados entre si ao longo dos anos de análise, indicando que as operadoras tinham diferentes retornos líquidos sobre os investimentos feitos, diferentes taxas de dívidas de curto prazo a serem pagas no exercício social e diferentes taxas de destinação das suas receitas para cobrir as despesas assistenciais de seus beneficiários.

Xavier, Souza e Avelar (2019) estudaram a relação entre o desempenho econômico-financeiro e as características das operadoras de saúde suplementar no período de 2010 a 2015, a partir do teste de Kolmogorov-Smirnov e teste de Kruskal-Wallis. Os autores chegaram a conclusão de que os indicadores financeiros estão relacionados com as características estudadas, sendo: a modalidade de autogestão, sede no interior, maior tempo no mercado e o pequeno porte, características consideradas como determinantes para obter um melhor desempenho econômico-financeiro. Os autores ainda destacam que a maioria dos indicadores econômico-financeiros apresentou diferenças estatisticamente significativas a depender da modalidade.

Em um estudo similar, Fernandes, Cailleau e Souza (2019) tiveram como objetivo avaliar padrões de comportamento dos indicadores econômicos financeiros das operadoras de planos de saúde nas classificações modalidade e região de atuação entre os anos 2010 e 2015, por meio da análise de variância - ANOVA. Como resultado, encontraram que a modalidade e a região de atuação da operadora estão relacionadas aos indicadores de rentabilidade, liquidez, atividade e endividamento.

Jesus et al. (2019) buscaram verificar se o desempenho financeiro é determinante do desempenho operacional das operadoras de saúde. Para isso, utilizaram o indicador econômico-financeiro e os indicadores de qualidade operacional, ou não financeiros, presentes no IDSS de 2011 a 2014. O IDSS neste estudo, assim como no de Sancovschi et al. (2014), estava composto pelas dimensões IDAS, IDEF, IDAO e IDSB. O autor concluiu que existe relação positiva entre o índice econômico-financeiro e os indicadores de qualidade operacional (não financeiros) do programa de qualificação da ANS.

\subsection{Hipótese de Pesquisa}

A partir das seções da revisão de literatura e pesquisas anteriores, foi possível chegar a importantes conclusões que são pontos de partida para este estudo. São elas:

1. A manutenção da solidez do mercado de saúde suplementar é relevante para a sociedade e economia do país. E como mencionado por Nogueira (2004), a prestação dos serviços de saúde está diretamente relacionada a situação financeira das operadoras. Portanto, faz-se necessária a presença de uma regulação que exerça um rigoroso acompanhamento econômico-financeiro das operadoras de saúde.

2. Os indicadores econômico-financeiros demonstraram-se relevantes para a análise de desempenho das operadoras de saúde. Estes são determinantes do desempenho operacional futuro (Jesus et al., 2019) e o desempenho econômico-financeiro insatisfatório está correlacionado com as instaurações de regimes especiais pela ANS em período subsequente (Sancovschi et al., 2014).

3. O grupo de indicadores calculados pela ANS considera os principais indicadores para análise de desempenho das operadoras de planos de saúde. Isto considerando o fato de que a maioria dos autores de pesquisas no setor de saúde suplementar utilizaram indicadores similares aos utilizados pela ANS para avaliar as operadoras de planos de saúde (dos 31 indicadores utilizados em pesquisas anteriores, 20 indicadores já são calculados periodicamente pela ANS). Esta ideia coaduna com o achado de Soares et al. (2009), que concluíram que a ANS utiliza os indicadores mais relevantes para a análise do setor. 
A partir do que foi apresentado, formula-se a seguinte hipótese de pesquisa:

H1: O desempenho econômico-financeiro insatisfatório está correlacionado com as instaurações dos regimes especiais pela ANS nas operadoras de planos de saúde.

O estudo busca comprovar esta hipótese de pesquisa e determinar ainda quais indicadores econômico-financeiros estão relacionados com as instaurações dos regimes especiais. A partir dessas informações, é esperado que as operadoras de saúde possam evitar a ocorrência de anormalidades graves e a consequente instauração de regimes especiais.

\section{Procedimentos Metodológicos}

Quanto à tipologia, esta pesquisa pode ser classificada como correlacional, empírica, quantitativa e ex post facto (Kumar, 2011; Kothari, 2004; Sampieri, Collado \& Lucio, 2013). Correlacional por estudar a relação existente entre os indicadores econômico-financeiros e as instaurações de regimes especiais nas operadoras. Empírico e quantitativo, uma vez que irá, por meio da análise dos dados e aplicação de métodos estatísticos, buscar a validação de hipóteses. E ex post facto, uma vez que utiliza dados derivados de eventos já ocorridos.

O objetivo deste estudo é analisar quais são os indicadores econômico-financeiros capazes de explicar a decisão da ANS de instaurar regimes especiais nas operadoras. Para isso, será utilizado o método de regressão logística. A regressão logística é formulada para prever e explicar uma variável categórica binária (Hair Júnior, Black, Babin, Anderson \& Tatham, 2009a), sendo o principal objetivo encontrar uma função logística que permita estabelecer a probabilidade de ocorrência do evento e a importância das variáveis para essa ocorrência (Fávero, Belfiore, Silva \& Chan, 2009a) - na seção 3.2 serão fornecidos maiores detalhes sobre a utilização do método.

A instauração de regimes especiais ocorre diante de anormalidades graves que podem resultar no cancelamento das operadoras, assim sendo, acredita-se que esse estudo se aproxime às pesquisas sobre previsão de falência. Nesse sentido, considerando o achado de Altman (1968) de que a falência pode ser prevista com precisão de até dois anos antes, o período de análise dos indicadores econômico-financeiros está relacionado à instauração dos regimes especiais nas operadoras nos anos de 2017, 2018 e 2019 , tendo sido estes coletados no período de 2015 a 2018.

A amostra inicial está inicialmente composta pelas operadoras ativas em 2019 que apresentaram seus indicadores calculados para os anos de 2015, 2016, 2017 e 2018 pertencentes as modalidades: cooperativa médica, cooperativa odontológica, medicina de grupo, odontologia de grupo, filantropia e seguradora especializada. As modalidades de autogestão e administradoras de benefícios não são consideradas devido às especificidades das mesmas

A população é composta por 1220 operadoras ativas em 2019. Após as exclusões das modalidades de autogestão e administradora de benefícios, restaram 911 operadoras. Devido à indisponibilidade de dados para todo o período da amostra, ainda foram removidas 196 operadoras. Sendo assim, a amostra inicial totalizou 715 operadoras, em que todas apresentaram os indicadores calculados para todos os anos de análise.

Para a aplicação da regressão logística, é formada outra amostra considerando as operadoras que entraram em regime especial no ano de 2017, 2018 e 2019. Foi levantado que 47 operadoras entraram em regime especial no ano de 2017, 40 operadoras entraram em regime especial no ano de 2018 e 46 operadoras entraram em regime especial no ano de 2019. Após a exclusão daquelas sem registo e às operadoras classificadas como autogestão restaram 37 operadoras em 2017, 34 operadoras em 2018 e 38 operadoras em 2019. Ainda foram excluídas aquelas que não estão presentes na amostra inicial, ou seja, aquelas que não possuíam os indicadores calculados para todo o período. Como consequência, as operadoras em que houve o decreto de liquidação extrajudicial ficaram fora da amostra. Desta forma, restaram 25 operadoras em 2017, 26 operadoras em 2018 e 26 operadoras em 2019, totalizando 77 ocorrências de regime especial de direção fiscal e técnica no período de 2017 a 2019.

Ainda para a aplicação da regressão logística, é necessário criar uma amostra espelho a partir da amostra de operadoras que entraram em regime especial nos anos de 2017, 2018 e 2019. Foram selecionadas na amostra inicial, de forma aleatória (procedimento realizado pelo Microsoft Excel 2016 por meio da função ALEATÓRIOENTRE), operadoras que não entraram em regime especial pertencentes a mesma modalidade e com sede na mesma região geográfica das operadoras em regime especial. Ou seja, para cada caso de regime especial, há um caso de normalidade. Sendo assim, amostra final possui 154 operadoras (77 em regime especial e 77 em regime normal de operação).

Além disso, é utilizado o método de reamostragem para reduzir as incertezas decorrentes da aleatoriedade na seleção das operadoras espelho. Neste estudo, o processo consiste em realizar mais dez vezes a seleção aleatória simples com reposição da amostra espelho, mantendo a similaridade das características modalidade e região geográfica com as operadoras em regime especial - por meio da 
função ALEATÓRIOENTRE do Microsoft Excel 2016. Assim, têm-se dez novas amostras para a aplicação da regressão logística.

\begin{tabular}{|c|c|}
\hline \multicolumn{2}{|c|}{ Etapa 1: Identificar todas as operadoras ativas em 2019.} \\
\hline Operadoras ativas em 2019 (populacão) & 1220 \\
\hline \multicolumn{2}{|c|}{$\begin{array}{c}\text { Etapa 2: Excluir as operadoras classificadas como autogestão e administradora de benefícios e aquelas que não possuem } \\
\text { todas as variáveis disponíveis para todo o período de } 2015 \text { a } 2018 .\end{array}$} \\
\hline (-) autogestão e administradora de benefícios & 309 \\
\hline (-) indisponibilidade de dados & 196 \\
\hline$=$ Amostra inicial (Análise Fatorial) & 715 \\
\hline \multicolumn{2}{|c|}{ Etapa 3: Identificar as operadoras que entraram em regime especial em 2017, 2018 e 2019.} \\
\hline Operadoras que entraram em regime especial & 133 \\
\hline \multicolumn{2}{|c|}{$\begin{array}{c}\text { Etapa 4: Excluir as operadoras classificadas como autogestão e administradora de benefícios e aquelas que não possuem } \\
\text { todas as variáveis disponíveis para todo o período de } 2015 \text { a } 2018 .\end{array}$} \\
\hline$(-)$ autogestão & 24 \\
\hline$(-)$ indisponibilidade de dados & 32 \\
\hline$=$ Amostra 1 (operadoras em Regime Especial) & 77 \\
\hline \multicolumn{2}{|c|}{$\begin{array}{l}\text { Etapa 5: Criar uma amostra espelho a partir da amostra de operadoras que entraram em regime especial nos anos de 2017, } \\
\qquad 2018 \text { e } 2019 \text { e chegar a amostra principal }\end{array}$} \\
\hline$=$ Amostra 2 (operadoras em normalidade) & 77 \\
\hline$=$ Amostra Total (Regressão Logística) & 154 (Amostra Principal - AP) \\
\hline \multicolumn{2}{|c|}{ Etapa 6: Realizar o processo de reamostragem, formando 10 novas amostras } \\
\hline$=$ Amostra 2 (operadoras em normalidade) $\times 10$ & 77 \\
\hline$=$ Amostra Total (Regressão Logística) $\times 10$ & 154 (Amostras 1 à $10-\mathrm{A} 1$ à $\mathrm{A} 10)$ \\
\hline
\end{tabular}

Figura 2 - Descrição das etapas para a definição da amostra

Fonte: Elaborado pelos autores

A coleta de dados foi realizada por meio da base de dados disponível no sítio eletrônico da ANS (www.ans.gov.br/), onde foram coletados os dados relativos aos indicadores do Anuário e às informações relativas às operadoras em que foram instaurados os regimes especiais. No entanto, não foi possível identificar todas as operadoras que entraram em regime especial no ano de 2017 pelo sítio eletrônico da ANS. Sendo assim, estes dados foram obtidos por meio do Sistema de Informação ao Cidadão (e-SIC).

Com relação às variáveis de estudo, optou-se por utilizar os indicadores econômico-financeiros presentes no Anuário dos anos de 2015, 2016, 2017 e 2018 que foram citados anteriormente na Figura 1. Porém, dessa lista de indicadores foram excluídos: ROE, DC e TM.

O ROE foi excluído do grupo de indicadores, pois, diante de um patrimônio líquido negativo, este se demonstra inconsistente. O TM foi descartado, pois seriam necessárias informações adicionais para uma interpretação mais assertiva, como por exemplo, a quantidade e perfil dos beneficiários. Além desses, o indicador DC também foi desconsiderado por apresentar muitos resultados inconsistentes ou faltantes.

Como dito por Matarazzo (2010), a avaliação conjunta dos prazos médios permite uma análise do ciclo operacional e de caixa das empresas. Dessa forma, os indicadores de Atividade, PMCR e PMPE, foram transformados em uma única variável de Ciclo Financeiro (PMPE - PMCR) que reflete a quantidade de dias que as operadoras possuem entre o pagamento de eventos indenizáveis e o recebimento das contraprestações. Se positivo, sinaliza que a operadora possui uma folga financeira, uma vez que o prazo de pagamento dos eventos é maior do que o de recebimento das contraprestações. Se negativo, a empresa precisa utilizar outras fontes de financiamento para o pagamento dos eventos que não as contraprestações.

Com isso, este estudo conta com um total de 15 indicadores provenientes do Anuário da ANS, que foram previamente subdivididos nos seguintes grupos: Estrutura de Capital, Rentabilidade, Liquidez, Despesas e Ciclo Financeiro.

\subsection{Análise Fatorial}

Em função do grande número de indicadores (frente ao tamanho da amostra sob análise), foram aplicadas análises fatoriais aos grupos descritos anteriormente no sentido de obter fatores que representassem cada dimensão e com isso reduzir o número de variáveis independentes no modelo logit. Para a aplicação da análise fatorial, foi considerada a amostra inicial do estudo, sendo composta por 715 operadoras com 15 indicadores por ano, no período de 2015 a 2018. Foi utilizado o programa Statistical Package for the Social Sciences 20 - SPSS 20.

Para verificar a qualidade da análise fatorial é observado os valores da estatística de Kaiser-MeyerOlkin (KMO $\geq 0,5)$, o teste de esfericidade de Bartlett ( $p$-valor $<0,05)$, o índice de Measure of Sampling Adequacy (MSA $\geq 0,5)$ e as comunalidades $(\geq 0,5)$. Tais parâmetros foram definidos tendo como base a literatura. Segundo Fávero, Belfiore, Silva \& Chan (2009b), valores abaixo de 0,5 para o KMO são considerados inaceitáveis. Hair Júnior, Black, Babin, Anderson e Tatham (2009b) afirmam que o MSA é considerado aceitável quando acima de 0,5 e que o nível mínimo para as comunalidades deve ser de 0,5. 
Com relação ao teste de Bartlett, o ideal é a rejeição da hipótese nula, uma vez que tal resultado sugere a existência de correlações significativas entre as variáveis (Fávero et al., 2009b), sendo utilizado o nível de $5 \%$ de significância para determinar se a hipótese nula deve ser aceita ou rejeitada.

O método de extração dos fatores foi a Análise dos Componentes Principais (ACP) e para a seleção do número de fatores, foi considerado o critério Kaiser com eigenvalues igual a 1. Além disso, optou-se pelo método ortogonal Varimax para evitar o problema de multicolinearidade entre as variáveis e obter uma separação mais clara dos fatores. Por fim, foram analisadas as cargas fatoriais considerando o mínimo de 0,30 para ser considerada significante, com base em Hair Júnior et al. (2009b).

No grupo Estrutura de Capital (IMOB, CE e ENDIV) não foi possível a construção de um fator. Mesmo diante de diferentes combinações para o grupo, na maioria dos casos, os valores de KMO e MSA não foram superiores a 0,5 e a variância explicada foi inferior à $60 \%$. Dessa forma, considerando a importância na utilização de pelo menos um indicador de estrutura de capital, optou-se por manter ENDIV no modelo da regressão logística. Esta escolha se deve ao fato deste indicador representar o endividamento total das operadoras, ou seja, no curto e no longo prazo.

Com relação ao grupo rentabilidade (ROA, MLB, MLL, EBIT e EBITDA), a análise fatorial com ROA, MLL e EBIT obteve resultados favoráveis para a estatística KMO e o teste de Bartlett. E a variância total explicada foi satisfatória, ficando entre $70,817 \%$ e $86,161 \%$. Sendo assim, o fator rentabilidade ficou composto por estes indicadores, uma vez que apresentaram os melhores resultados. Além disso, considerando os resultados das demais análises fatoriais do grupo rentabilidade, verificou-se que a presença do EBITDA aumenta a variância explicada em parte dos modelos. Portanto, este indicador também é mantido no modelo da regressão logística, porém de forma isolada.

Os indicadores de liquidez (LG e LC) apresentam bons resultados para a estatística KMO, teste de Bartltett, MSA e comunalidade. Além disso, a variância total explicada é alta para todos os anos, variando entre $96,174 \%$ e $97,208 \%$. Sendo assim, o fator liquidez composto por LG e LC é mantido para a análise de regressão logística.

No grupo de despesas (DM, DA, COMB e COMBA), a combinação DA, COMB e COMBA apresentou os melhores resultados - a estatística KMO, o Teste de Bartlett, MSA e comunalidades permaneceram dentro dos padrões aceitáveis e a variância total explicada ficou entre $79,277 \%$ e 82,646\%. Deste modo, fator despesas é composto por DA, COMB e COMBA. Além disso, percebeu-se que nos modelos com DM, boa parte da variância total era em virtude desse indicador. Com isso, decidiu-se pela inclusão isolada do mesmo no modelo logit.

O grupo ciclo financeiro é formado apenas pelo indicador PMPE - PMCR, que não possui correlação alta com nenhum dos outros indicadores, não sendo possível sua inclusão em nenhum dos outros fatores formados. Sendo o indicador de ciclo financeiro o único que considera as informações provenientes dos prazos médios e fornece uma compreensão complementar acerca da liquidez das operadoras, optou-se por não o desprezar e considerá-lo isoladamente no modelo da regressão logística.

\begin{tabular}{|c|c|c|c|}
\hline \multirow[b]{2}{*}{ Grupos } & \multicolumn{3}{|c|}{ Variáveis de Estudo } \\
\hline & \multicolumn{2}{|l|}{ Antes da aplicação da Análise Fatorial } & $\begin{array}{c}\text { Após aplicação da Análise Fatorial } \\
\text { (variáveis independentes da logit) }\end{array}$ \\
\hline \multirow{3}{*}{$\begin{array}{l}\text { Estrutura de } \\
\text { Capital }\end{array}$} & Imobilização do Ativo Total & IMOB & \multirow{3}{*}{ Indicador ENDIV } \\
\hline & Endividamento & ENDIV & \\
\hline & Composição do endividamento & CE & \\
\hline \multirow{5}{*}{ Rentabilidade } & Retorno sobre o Ativo Total & $\mathrm{ROA}$ & \multirow{5}{*}{$\begin{array}{c}\text { Fator Rentabilidade (ROA, MLL e EBIT) e Indicador } \\
\text { EBITDA }\end{array}$} \\
\hline & Margem de Lucro Bruto & MLB & \\
\hline & Margem de Lucro Líquido & MLL & \\
\hline & Margem EBIT (LAJIR) & EBIT & \\
\hline & Margem EBITDA (LAJIDA) & EBITDA & \\
\hline \multirow{2}{*}{ Liquidez } & Liquidez Geral & LG & \multirow{2}{*}{ Fator Liquidez (LG e LC) } \\
\hline & Liquidez Corrente & LC & \\
\hline \multirow{4}{*}{ Despesas } & Índice Despesas Médicas (sinistralidade) & DM & \multirow{4}{*}{$\begin{array}{l}\text { Fator Despesas (DA, COMB e COMBA) e Indicador } \\
\text { DM }\end{array}$} \\
\hline & Índice de Despesas Administrativas & $\mathrm{DA}$ & \\
\hline & Índice Combinado & COMB & \\
\hline & Índice Combinado Ampliado & COMBA & \\
\hline Ciclo Financeiro & $\begin{array}{l}\text { Prazo Médio de Pagamento de Eventos - } \\
\text { Prazo Médio de Contraprestações a Receber }\end{array}$ & $\begin{array}{l}\text { PMPE - } \\
\text { PMCR }\end{array}$ & Indicador PMPE - PMCR \\
\hline
\end{tabular}

Figura 3 - Resultados da seleção de variáveis independentes por meio da Análise Fatorial Fonte: Elaborado pelos autores

Com esses resultados da seleção de variáveis independentes, a regressão logística contou com as variáveis ENDIV, EBITDA, DM e PMPE - PMCR, além dos Fatores de Rentabilidade (ROA, MLL e EBIT), de Liquidez (LG e LC) e de Despesa (DA, COMB e COMBA). Obteve-se, então uma redução de quinze para sete variáveis independentes. 


\subsection{Regressão Logística}

A regressão logística, também conhecida como logit, é uma técnica estatística utilizada para estudar o comportamento entre uma variável dependente binária e variáveis explicativas métricas ou não métricas (Fávero et al., 2009a). O que difere a regressão logística das demais é o fato de que os valores previstos jamais podem estar fora do domínio 0 e 1 (Hair Júnior et al., 2009a).

O método de regressão logística foi empregado neste estudo com o objetivo de analisar a capacidade dos fatores formados por indicadores econômico-financeiros, resultantes da aplicação da técnica de análise fatorial, em explicar a decisão da ANS de instaurar regimes especiais nas operadoras em período subsequente. Também foi utilizado o programa SPSS 20.

A variável dependente é a operadora ter entrado (1) ou não (0) na condição de regime especial nos anos de 2017, 2018 e 2019. E as variáveis explicativas são os fatores e indicadores econômico-financeiros um ano antes da ocorrência do evento e dois anos antes da ocorrência do evento. Sendo assim, o método de regressão será aplicado em dois momentos: t-1 e t-2.

A função da regressão logística ficou composta como descrito a seguir:

$$
R E=\beta_{0}+\beta_{1} A F_{R E N T}+\beta_{2} A F_{D E S P}+\beta_{3} A F_{L I Q}+\beta_{4} Z E N D I V+\beta_{5} Z E B I T D A+\beta_{6} Z D M+\beta_{7} Z P M P E P M C R
$$

Sendo:

$\mathrm{RE}$ - A empresa ter entrado em regime especial (1) ou não (0) nos anos de 2017, 2018 e 2019

$\beta n \quad-$ Coeficientes

AF_RENT - Fator Rentabilidade em t-1 ou t-2

AF_DESP - Fator Despesa em t-1 ou t-2

AF LIQ - Fator Liquidez em t-1 ou t-2

ZENDNIV - Indicador ENDIV Padronizado em t-1 ou t-2

ZEBITDA - Indicador EBITDA Padronizado em t-1 ou t-2

ZDM - Indicador DM Padronizado em t-1 ou t-2

ZPMPEPMCR - Indicador PMPE - PMCR Padronizado em t-1 ou t-2

A principal premissa da regressão logística é ter multicolinearidade aceitável (Fávero et al., 2009a). Nesse sentido, Gujarati e Porter (2011) mencionam que uma correlação superior a 0,8 pode indicar um problema de multicolinearidade. Portanto, a primeira etapa foi avaliar se as correlações existentes entre as variáveis independentes indicavam multicolinearidade.

Após a análise de correlação, realizou-se a aplicação da regressão logística. Como a amostra do estudo é equilibrada, o ponto de corte utilizado foi de 0,5. Além disso, o método "Inserir" é utilizado, pois utiliza todas as variáveis selecionadas pelo pesquisador (Fávero et al., 2009a) e, no primeiro momento, temse o objetivo de que todas as variáveis permaneçam no modelo.

Em seguida, de acordo com Fávero et al. (2009a), as informações de qualidade e ajuste do modelo são analisadas: Tabela de Classificação, Teste Omnibus, Teste de Hosmer e Lemeshow, Curva ROC, além da taxa de acerto de classificação e do R2 de Nagelkere. Por fim, após verificar a qualidade e ajuste do modelo, observou-se a relação existente entre as variáveis independentes e a variável dependente, bem como a significância das variáveis que compõe o modelo. A partir disso, foi possível identificar a influência de cada uma das variáveis independentes para a ocorrência do evento.

Para que os resultados fossem validados, este mesmo processo foi feito novamente para dez novas amostras (todas equilibradas). Ainda para reforçar os achados, todas as amostras foram também submetidas à análise de robustez. Esta etapa se diferencia da anterior pela aplicação do método "Retroceder: Wald", que inicia o modelo com todas as variáveis e as retira uma a uma com base na probabilidade da estatística de Wald (Brooks, 2019). Sendo assim, esta etapa se diferencia da anterior, pois as variáveis que permanecem no modelo são apenas as significativas.

$\mathrm{Na}$ Figura 4 está descrita o comportamento esperado dos fatores e indicadores financeiros em relação à probabilidade de ocorrência dos regimes especiais, tendo como base a interpretação dos indicadores que constam na literatura.

\begin{tabular}{|l|l|c|}
\hline \multicolumn{1}{|c|}{ Variáveis } & \multicolumn{1}{c|}{ Sigla } \\
\hline Fator Rentabilidade & AF_RENT & Negativo \\
\hline Fator Despesa & AF_DESP & Positivo \\
\hline Fator Liquidez & AF_LIQ & Negativo \\
\hline Indicador Ebitda & ZEBITDA & Negativo \\
\hline Indicador Despesas Médicas & ZDM & Positivo \\
\hline Indicador Endividamento & ZENDIV & Positivo \\
\hline Indicador Ciclo Financeiro & ZPMPEPMCR & Negativo \\
\hline
\end{tabular}

Figura 4 - Sinais esperados na regressão logística

Fonte: Elaborado pelos autores. 


\subsection{Limitações do estudo}

A principal limitação deste estudo é que seus resultados não podem ser generalizados. Isto porque estes são influenciados diretamente pela disponibilidade e qualidade dos dados, além do fato de corresponder à um período específico.

Os indicadores utilizados no estudo são calculados pela ANS com base nas informações contábeis enviadas ao órgão regulador pelas operadoras. Desta forma, não é possível garantir a qualidade destes dados, pois não foram calculados pelo pesquisador.

É importante admitir a possibilidade de que fatores políticos tenham influenciado as decisões de intervenção da ANS nas operadoras. Além disso, mudanças econômicas, no comportamento dos consumidores ou na legislação, ocorridas no período estudado, impactam o desempenho das operadoras. Estes e outros fatores não controláveis pelo pesquisador exercem influência sobre os resultados do estudo.

\section{Análise dos Resultados}

A análise de regressão logística atende ao objetivo de analisar quais são os indicadores econômicofinanceiros capazes de explicar a decisão da ANS de instaurar regimes especiais nas operadoras. $\mathrm{Na}$ Tabela 1, estão dispostos os resultados da regressão para t-1 e t-2 da amostra principal de 154 operadoras, sendo 77 em regime especial e 77 em normalidade, considerando o método inserir. Os resultados para t-1 e t-2 são similares.

Observa-se que as correlações existentes entre as variáveis independentes não sugerem multicolinearidade e, portanto, não foi necessário fazer nenhuma alteração no modelo. Os resultados dos testes mostram um bom ajuste do modelo, destaca-se que a variância explicada foi de $55,8 \%$ em t- 1 e $53,4 \%$ em t-2 - o que indica que mais de $50 \%$ da variação na condição das operadoras é explicada pelas variáveis explicativas. Com relação a equação resultante, verifica-se que em ambos os testes, as variáveis que apresentaram significância foram o AF_LIQ, ZENDIV e ZPMPEPMCR, o que indica que elas são estatisticamente diferentes de zero.

Tabela 1:

Resultados da análise de regressão para a amostra principal

\begin{tabular}{|c|c|c|}
\hline & $t-1$ & $t-2$ \\
\hline \multicolumn{3}{|l|}{ Análise de Correlação } \\
\hline Correlações acima de 0,80 & Nenhuma & Nenhuma \\
\hline \multicolumn{3}{|l|}{ Modelo com todas as variáveis } \\
\hline Tabela de Classificação & $78,6 \%$ de acerto & $78,6 \%$ de acerto \\
\hline Teste Omnibus (Modelo) & Rejeita $\mathrm{H} 0(0,000)$ & Rejeita H0 $(0,000)$ \\
\hline Teste Hosmer e Lemeshow & Aceita HO $(0,974)$ & Aceita $\mathrm{HO}(0,106)$ \\
\hline \multirow{2}{*}{$\begin{array}{l}\text { Nagelkere } \mathrm{R}^{2} \\
\text { Curva ROC: Área abaixo da curva e } \\
\text { significância }\end{array}$} & 0,558 & 0,534 \\
\hline & $0,833(0,000)$ & $0,815(0,000)$ \\
\hline g & $\begin{array}{c}-2,303^{* * *}+0,339 \text { AF RENT - 0,923 } \\
\text { AF_DESP - 4,390**A AF_LIQ - 0,457 } \\
\text { ZEBITDA - 0,612 ZDM + 2,901*** Z ENDIV } \\
-0,445^{\star} \text { ZPMPEPMCR }\end{array}$ & $\begin{array}{c}-2,299^{* * *}-0,032 \text { AF_RENT - 1,192 } \\
\text { AF_DESP }-4,680^{* * *} \text { AF_LIQ - 1,112 } \\
\text { ZEBITDA - 0,224 ZDM + 1,293** ZENDIV - } \\
0,679^{* *} \text { ZPMPEPMCR }\end{array}$ \\
\hline
\end{tabular}

*** significante ao nível de $1 \% ;{ }^{* *}$ significante ao nível de $5 \%$; *significante ao nível de $10 \%$
Fonte: Elaborado pelos autores.

Para confirmar estes resultados o mesmo procedimento foi refeito para 10 novas amostras (A1 à A10). Na Tabela 2, são apresentados os resultados predominantes e médios para t-1 e t-2 dessas novas amostras.

É possível observar que, de forma geral, os resultados não indicam problema de multicolinearidade entre as variáveis independentes. Porém, destaca-se que, no modelo para t-2, A2 e A10 apresentaram correlação um pouco superior a 0,80 entre AF_RENT e ZEBITDA (respectivamente 0,816 e 0,829).

Com relação ao ajuste dos modelos, os resultados são todos favoráveis, com uma média de $54,6 \%$ (t-1) e 54,7\% (t-2) de variância explicada - novamente foi encontrado que mais de $50 \%$ da variação na condição das operadoras é explicada pelas variáveis independentes. Destaca-se que a A8 em t-2, o teste Hosmer e Lemeshow só pode ser aceito considerando o nível de 1\% de significância.

Considerando as variáveis significativas e a relação das mesmas com a variável dependente, os resultados para $A 1$ à $A 10$ confirmam os achados obtidos a partir da amostra principal. Verifica-se que as variáveis $A F \_L I Q$, ZENDIV e ZPMPEPMCR são significantes na maioria dos casos, com destaque para AF_LIQ em t-1 e AF_LIQ e ZENDIV em t-2 em que obtiveram $100 \%$ de ocorrência. Além disso, os sinais dos coeficientes se mantiveram. 
Em alguns modelos, a variável ZDM aparece como significativa. No entanto, além desta variável apresentar baixa ocorrência (20\% em t-1 e 10\% em t-2), os sinais também se demonstraram inconsistentes, divergindo entre $\mathrm{t}-1$ e $\mathrm{t}-2$.

Tabela 2:

Resultados predominantes/médios da análise de regressão para A1 à A10

\begin{tabular}{lcc}
\hline & t-1 & t-2 \\
\hline Análise de Correlação & Nenhuma & Nenhuma \\
\hline Correlações acima de 0,80 & & $77,60 \%$ de acerto \\
Modelo com todas as variáveis & Rejeita H0 \\
Tabela de Classificação & $78,51 \%$ de acerto & Aceita H0 \\
Teste Omnibus (Modelo) & Rejeita H0 & 0,547 \\
Teste Hosmer e Lemeshow & Aceita H0 & $0,820(0,000)$ \\
$\quad$ Nagelkere R ${ }^{2}$ & 0,546 & $100 \%$ (negativo) \\
Curva ROC: Área abaixo da curva e & $0,826(0,000)$ & $10 \%$ (negativo) \\
significância & & $100 \%$ (positivo) \\
Variáveis significativas até 10\% & & $60 \%$ (negativo) \\
(\% ocorrência e relação) & $100 \%$ (negativo) &
\end{tabular}

Fonte: Elaborado pelos autores.

Diante destes resultados, são variáveis significantes: AF_LIQ, ZENDIV e ZPMPEPMCR. Analisando ainda a média da razão de chances destas variáveis, tem-se que:

- O aumento de uma unidade de AF_LIQ faz a probabilidade da ocorrência do evento reduzir em aproximadamente $98 \%$.

- O aumento de uma unidade de ZENDIV faz a probabilidade da ocorrência do evento aumentar em aproximadamente $710 \%$.

- O aumento de uma unidade de ZPMPEPMCR faz a probabilidade da ocorrência do evento reduzir em aproximadamente $24 \%$. inferências:

Além disso, com base no sinal dos coeficientes apresentados por elas, é possível fazer as seguintes

- Quanto menor a liquidez, maior a probabilidade de estar em regime especial.

- Quanto maior o endividamento, maior a probabilidade de estar em regime especial.

- Quanto menor a folga financeira, maior a probabilidade de estar em regime especial.

Para reforçar os resultados encontrados, todas as amostras foram também submetidas à análise de robustez, que consistiu na aplicação da regressão com o método "Retroceder: Wald" em todas as amostras.

Para um melhor entendimento, primeiro são apresentados os resultados para a amostra principal (Tabela 3) e, em seguida, para A1 à A10 (Tabela 4). Os resultados de correlação não são relatados pois são os mesmos da Tabela 2. Com relação à qualidade e ajuste do modelo, os resultados foram favoráveis. Cabe ressaltar que na análise de robustez para $A 1$ à $A 10$, o teste de Hosmer e Lemeshow em uma das amostras (A7) só pode ser aceito considerando o nível de 1\% de significância.

Pode-se observar por meio da Tabela 3, que mais uma vez os resultados se reforçam em t-1 e t-2 para a amostra principal, em que as mesmas variáveis se mantêm significantes e os respectivos sinais se repetem. A partir da Tabela 4, verifica-se que os sinais das variáveis significativas são iguais aos dos testes anteriores. As variáveis AF_LIQ e ZENDIV se mantêm significantes na maioria dos casos em ambos os modelos, enquanto a variável ZPMPEPMCR tem sua ocorrência reduzida para $50 \%$ em t-1 e $40 \%$ em t-2. Além disso, as variáveis AF_RENT, ZEBITDA e ZDM aparecem como significantes, no entanto, este resultado não é recorrente entre as amostras.

Além disso, ao analisar a média da razão de chances das variáveis AF_LIQ, ZENDIV e ZPMPEPMCR, tem-se que:

- O aumento de uma unidade de AF_LIQ faz a probabilidade da ocorrência do evento reduzir em aproximadamente $98 \%$.

- O aumento de uma unidade de ZENDIV faz a probabilidade da ocorrência do evento aumentar em aproximadamente $654 \%$. 
- O aumento de uma unidade de ZPMPEPMCR faz a probabilidade da ocorrência do evento reduzir em aproximadamente $45 \%$.

Tabela 3:

Resultados da análise de robustez para a amostra principal

\begin{tabular}{|c|c|c|}
\hline & $t-1$ & $t-2$ \\
\hline \multicolumn{3}{|l|}{ Modelo com todas as variáveis } \\
\hline Tabela de Classificação & $77,9 \%$ de acerto & $76,0 \%$ de acerto \\
\hline Teste Omnibus (Modelo) & Rejeita H0 $(0,000)$ & Rejeita H0 $(0,000)$ \\
\hline Teste Hosmer e Lemeshow & Aceita $\mathrm{HO}(0,342)$ & Aceita $\mathrm{HO}(0,177)$ \\
\hline Nagelkere $R^{2}$ & 0,529 & 0,508 \\
\hline $\begin{array}{l}\text { Curva ROC: Área abaixo da curva e } \\
\text { significância }\end{array}$ & $0,822(0,000)$ & $0,802(0,000)$ \\
\hline Equação & $\begin{array}{c}-1,960^{*}-3,538^{*} \text { AF_LIQ }+2,845^{*} \text { ZENDIV - } \\
0,485^{* *} \text { ZPMPEPMCR }\end{array}$ & $\begin{array}{c}-1,994^{*}-4,279^{*} \text { AF_LIQ }+1,238^{*} \text { ZENDIV - } \\
0,654^{* *} \text { ZPMPEPMCR }\end{array}$ \\
\hline \multicolumn{3}{|c|}{$\begin{array}{l}\text { significante ao nível de } 1 \% ;{ }^{* *} \text { significante ao nível de } 5 \% \\
\text { Fonte: elaborado pelos autores }\end{array}$} \\
\hline \multicolumn{3}{|c|}{$\begin{array}{l}\text { Tabela 4: } \\
\text { Resultados da análise de robustez para } \mathrm{A} 1 \text { à } \mathrm{A} 10\end{array}$} \\
\hline & $t-1$ & $\mathrm{t}-2$ \\
\hline \multicolumn{3}{|l|}{ Modelo com todas as variáveis } \\
\hline Tabela de Classificação & $78,2 \%$ de acerto & $76,4 \%$ de acerto \\
\hline Teste Omnibus (Modelo) & Rejeita HO & Rejeita $\mathrm{HO}$ \\
\hline Teste Hosmer e Lemeshow & Aceita $\mathrm{H} 0$ & Aceita $\mathrm{HO}$ \\
\hline Nagelkere $\mathrm{R}^{2}$ & 0,530 & 0,531 \\
\hline $\begin{array}{l}\text { Curva ROC: Área abaixo da curva e } \\
\text { significância }\end{array}$ & 0,818 & 0,812 \\
\hline \multicolumn{3}{|l|}{$\begin{array}{l}\text { Variáveis significativas até } 10 \% \\
\text { (\% ocorrência e relação) }\end{array}$} \\
\hline AF_RENT & $10 \%$ (negativo) & $10 \%$ (negativo) \\
\hline$A F \_L I Q$ & $100 \%$ (negativo) & $100 \%$ (negativo) \\
\hline ZEBITDA & $0 \%(-)$ & $30 \%$ (negativo) \\
\hline ZDM & $20 \%$ (positivo) & $0 \%(-)$ \\
\hline ZENDIV & $80 \%$ (positivo) & $100 \%$ (positivo) \\
\hline ZPMPEPMCR & $50 \%$ (negativo) & $40 \%$ (negativo) \\
\hline
\end{tabular}

Fonte: elaborado pelos autores.

Vale ressaltar ainda que as regressões obtiveram um Nagelkere $R^{2}$ médio de $53,7 \%$ e um acerto médio de $77,3 \%$ de classificação dos casos de regime especial de direção técnica e fiscal. Sendo assim, pode-se afirmar que o modelo possui uma boa explicação e que $77,3 \%$ da ocorrência de regimes especiais puderam ser previstos somente com a informação proveniente dos indicadores econômico-financeiros em anos anteriores.

Deste modo, conclui-se que as variáveis que estão fortemente relacionadas à instauração de regimes especiais são $A F \_L I Q$ e ZENDIV, pois elas são significantes quase na totalidade de testes realizados e também apresentam uma maior influência sobre a ocorrência do evento. Já a variável ZPMPEPMCR parece estar relacionada, mas de maneira mais fraca, uma vez que essa relação se demostrou significativa em um menor número de amostras (aproximadamente a metade) e também demonstrou ter menor impacto sobre a ocorrência do evento. Ainda é possível destacar que a variável ENDIV, que representa o endividamento total das operadoras, foi o indicador que mais demonstrou possuir impacto sobre a instauração dos regimes especiais quando considerada a razão de chances.

Desta forma, a $\mathrm{H} 1$ de que "o desempenho econômico-financeiro insatisfatório está correlacionado com as instaurações dos regimes especiais pela ANS nas operadoras de planos de saúde" pode ser confirmada. Sendo assim, os resultados apontam que quanto menor a liquidez, maior o endividamento e menor a folga financeira, maior a probabilidade de instauração dos regimes especiais de direção fiscal e técnica, podendo esta ser prevista até 2 anos antes de sua ocorrência.

Este resultado está de acordo com Sancovschi et al. (2014) que encontraram que as intervenções realizadas pela ANS estavam relacionadas de forma negativa à dimensão econômica e financeira do IDSS, um ano e dois anos antes da sua ocorrência. No entanto, tal estudo não forneceu indícios sobre quais indicadores econômico-financeiros eram os mais relevantes para a decisão de instauração dos regimes especiais pela ANS.

Nesse sentido, este trabalho somou informações ao encontrar que a liquidez, o endividamento e o ciclo financeiro estão relacionados com a instauração dos regimes especiais. Sendo os indicadores de 
liquidez geral, liquidez corrente e o indicador de endividamento, os mais representativos para a instauração de regimes especiais - uma vez que as variáveis AF_LIQ e ZENDIV apresentaram significância em praticamente todos os testes realizados e com as diferentes amostras.

Os resultados encontrados possibilitam que as operadoras de saúde tenham uma melhor gestão financeira, com um foco maior nos aspectos de liquidez e endividamento, com o objetivo de evitar a ocorrência de anormalidades graves e a consequente instauração de regimes especiais. Nesse sentido, a pesquisa contribui para um maior conhecimento sobre análise de desempenho nas operadoras de saúde, com a identificação das dimensões financeiras que são determinantes para a instauração de regimes especiais.

\section{Considerações Finais}

Esta pesquisa teve como objetivo principal analisar quais são os indicadores econômico-financeiros capazes de explicar a decisão da ANS de instaurar regimes especiais nas operadoras, considerando os indicadores econômico-financeiros do período de 2015 a 2019 e as instaurações de regimes especiais ocorridas de 2017 a 2019. Foi utilizada a técnica de análise fatorial com a finalidade de reduzir os indicadores para serem utilizados como insumo da regressão logística. As variáveis independentes da regressão logística foram: fator rentabilidade, fator liquidez, fator despesas, indicador margem ebitda, indicador endividamento, indicador despesa médica e indicador ciclo financeiro. Enquanto isso, a variável dependente foi a operadora ter entrado (1) ou não (0) na condição de regime especial no período de 2017 a 2019.

A logit teve como amostra 77 operadoras que estavam em regime especial e 77 operadoras que não estavam em regime especial. Lembrando que, diante da indisponibilidade de dados para o período analisado, as operadoras que entraram em liquidação extrajudicial foram excluídas da amostra.

A regressão logística foi realizada para t-1 e t-2 e foi feito o processo de reamostragem e análise de robustez. Ao todo foram utilizados dois métodos (Inserir e Retroceder: Wald) que foram aplicados em um total de 11 diferentes amostras aleatórias simples com reposição. Os resultados foram similares para todas as amostras nos dois métodos utilizados. Foram resultados encontrados:

1. As variáveis que estão fortemente relacionadas à instauração de regimes especiais de direção fiscal e técnica são o fator liquidez (LG e LC) e o indicador endividamento (ENDIV), sendo estas significativas em quase todas as amostras estudadas e testes realizados, tendo demonstrado ter influência sobre a probabilidade de ocorrência do evento.

2. O indicador ciclo financeiro (PMPE - PMCR) parece estar relacionado com a instauração de regimes especiais de direção fiscal e técnica, mas de maneira mais fraca, uma vez que essa relação se demostrou significativa em pouco mais da metade das amostras estudadas e testes realizados, além de demonstrar ter a menor influência sobre a probabilidade de ocorrência do evento.

3. Quanto menor a liquidez, maior o endividamento e menor a folga financeira, maior a probabilidade de instauração dos regimes especiais de direção fiscal e técnica, podendo esta ser prevista até 2 anos antes de sua ocorrência.

4. Confirmação da $\mathrm{H} 1$ de que o desempenho econômico-financeiro insatisfatório está correlacionado com as instaurações dos regimes especiais pela ANS nas operadoras de planos de saúde.

Estes resultados apontam para a importância dos indicadores econômico-financeiros na avaliação de desempenho das operadoras de saúde, dada a sua capacidade de prever a instauração dos regimes especiais de direção técnica e fiscal.

A relação entre o desempenho econômico-financeiro insatisfatório com as instaurações dos regimes especiais, bem como, a capacidade de previsão com até 2 anos de antecedência, são resultados alinhados ao estudo de Sancovschi et al. (2014), em que os autores encontraram que as intervenções realizadas pela ANS nas operadoras de saúde em 2009 estavam significativamente relacionadas à dimensão econômicofinanceira em 2007 e 2008 (negativamente). Este trabalho ainda contribui com a informação sobre quais aspectos econômico-financeiros são os mais relevantes para a decisão de instauração dos regimes especiais pela ANS.

Foi possível concluir que a situação econômico-financeira das operadoras é fator relevante para a determinação dos regimes especiais de direção fiscal e técnica, principalmente os aspectos relacionados a liquidez e endividamento. Este achado vai ao encontro ao estudo de Soares et al. (2009) que encontrou que os indicadores liquidez corrente e liquidez geral estão entre os mais relevantes para avaliar o desempenho das operadoras. E também ao achado de Kudlawicz (2013) de que as empresas com menor rentabilidade buscam seus recursos em terceiros e no curto prazo, ou seja, são mais endividadas.

Sendo assim, pode-se dizer que operadoras com grandes níveis de endividamento tem sua rentabilidade comprometida e consequente maiores chances de entrar em regimes especiais. Considerando 
que os indicadores de liquidez demonstram a capacidade de pagamento de dívidas da empresa (Matarazzo, 2010), também é possível inferir que operadoras com maiores níveis de endividamento, podem ter maior dificuldade para manter uma boa liquidez.

Com base nos resultados deste trabalho, cabe o questionamento acerca da utilização de indicadores não financeiros pela ANS para avaliar as operadoras, como ocorre com o IDSS que conta com indicadores majoritariamente não financeiros. Lembrando que o IDSS tem o objetivo de fornecer informações que auxiliem os consumidores na escolha do plano de saúde, não seria o desempenho financeiro das operadoras informação essencial à população, uma vez que os resultados financeiros desfavoráveis estão relacionados às instaurações dos regimes especiais?

No caso das operadoras de saúde, os resultados forneceram informações sobre quais indicadores ou aspectos financeiros devem ser acompanhados com mais atenção a fim de reduzirem as chances de entrarem em regime especial. Neste sentido, os achados reforçam a importância das operadoras em possuir uma boa administração de capital de giro, a fim de manter uma liquidez favorável e utilizar mais fontes espontâneas de financiamento. Ou seja, as operadoras devem buscar uma boa capacidade de pagamento com uma menor dependência de recursos de terceiros, pois desse modo são capazes de reduzir as chances de ter por problemas financeiros e passar por um regime especial.

O bom funcionamento do setor de saúde suplementar está relacionado, portanto, com a capacidade das empresas em se manterem solventes - como mencionado por Nogueira (2004). Sendo assim, uma administração financeira ineficaz constitui risco ao fornecimento dos serviços de saúde aos beneficiários e ao sistema de saúde como um todo.

Apesar dos indícios de que a situação econômico-financeira seja fator relevante para a instauração de regimes especiais pela ANS, deve-se considerar a existência de outras variáveis não controlados por esta pesquisa - como, por exemplo, fatores políticos e econômicos. Desta forma, considera-se haver outros aspectos envolvidos nas decisões da ANS.

Como complemento a esta pesquisa, seria interessante verificar se os fatores determinantes para a instauração do regime especial são os mesmos entre direção técnica e direção fiscal. Além disso, outro trabalho relevante seria estudar de forma detalhada a situação econômico-financeira em anos anteriores a ocorrência da liquidação extrajudicial, acompanhando a transição da situação de normalidade até o encerramento do regime de liquidação extrajudicial.

\section{Referências}

Altman, E. I. (1968). Financial ratios, discriminant analysis and the prediction of corporate bankruptcy. The Journal of Finance, 23 (4), 589-609. DOI: http://dx.doi.org/10.1111/i.1540-6261.1968.tb00843.x

Agência Nacional de Saúde Suplementar (2012a). Resolução Normativa No 316, de 30 de novembro 2012. Dispõe sobre os regimes especiais de direção fiscal e de liquidação extrajudicial sobre as operadoras de planos de assistência à saúde [...]. Rio de Janeiro: ANS. Recuperado em 28 de março de 2019, de : http://www.ans.gov.br/component/legislacao/?view=legislacao\&task=TextoLei\&format=raw\&id=MjMxNA==

Agência Nacional de Saúde Suplementar (2012b). Resolução Normativa $n^{\circ}$ 307, de 22 de outubro de 2012. Dispõe sobre os procedimentos de adequação econômico-financeira das operadoras de planos privados de assistência à saúde [...]. Rio de Janeiro: ANS. Recuperado em 28 de março de 2019, de : http://www.ans.gov.br/component/legislacao/?view=legislacao\&task=TextoLei\&format=raw\&id=Mjl4MQ==

Agência Nacional de Saúde Suplementar (2015). Resolução Normativa $n^{\circ}$ 386, de 9 de outubro de 2015. Dispõe sobre o Programa de Qualificação de Operadoras e dá outras providências. Rio de Janeiro: ANS. Recuperado em 29 de março de 2019, de:

http://www.ans.gov.br/component/legislacao/?view=legislacao\&task=TextoLei\&format= raw\&id=MzEwMA $==$

Agência Nacional de Saúde Suplementar (2016a). Resolução Normativa $N^{\circ}$ 400, de 25 de fevereiro de 2016. Dispõe sobre os parâmetros e procedimentos de acompanhamento econômico-financeiro das operadoras de planos privados de assistência à saúde e de monitoramento estratégico do mercado de saúde suplementar. Rio de Janeiro: ANS. Recuperado em 03 de abril de 2019, de:

http://www.ans.gov.br/component/legislacao/?view=legislacao\&task=PDFAtualizado\&format=raw\&id=MzlwN $\underline{Q}$

Agência Nacional de Saúde Suplementar (2016b). Resolução normativa $N^{\circ}$ 417, de 22 de dezembro de 2016. Dispõe sobre o Plano de Recuperação Assistencial e sobre o regime especial de Direção Técnica, no âmbito do mercado de saúde suplementar [...]. Rio de Janeiro: ANS. Recuperado em 03 de abril de 2019, de: http://www.ans.gov.br/ component/legislacao/?view=legislacao\&task=TextoLei\&format=raw\&id=MzM0OQ== 
Agência Nacional de Saúde Suplementar (2016c). Anuário 2015: Aspectos econômico-financeiros das operadoras de plano de saúde. Rio de Janeiro: ANS. Recuperado em 28 de maio de 2019, de:

http://www.ans.gov.br/aans/quem-somos/108-materiais-para-pesquisas/2953-anuario-aspectos-economicofinanceiros-das-operadoras-de-plano-de-saude

Agência Nacional de Saúde Suplementar (2016d). Ficha técnica dos indicadores do Programa de Qualificação de Operadoras (ano base 2015). Rio de Janeiro: ANS. Recuperado em 29 de maio de 2019, de: http://www.ans.gov.br/perfil-do-setor/dados-e-indicadores-do-setor/dados-do-programa-de-qualificacaode-operadoras

Agência Nacional de Saúde Suplementar (2017a). Anuário 2016: Aspectos econômico-financeiros das operadoras de plano de saúde. Rio de Janeiro: ANS. Recuperado em 28 de maio de 2019, de:

http://www.ans.gov.br/aans/quem-somos/108-materiais-para-pesquisas/2953-anuario-aspectos-economicofinanceiros-das-operadoras-de-plano-de-saude

Agência Nacional de Saúde Suplementar (2017b). Relatório da qualificação das operadoras 2017 (ano base 2016). Rio de Janeiro: ANS. Recuperado em 30 de maio de 2019, de:

http://www.ans.gov.br/images/stories/Materiais para

pesquisa/Perfil setor/idss/pqo2017 relatorio da qualificacao operadoras.pdf

Agência Nacional de Saúde Suplementar (2017c). Ficha técnica dos indicadores do Programa de Qualificação de Operadoras (ano base 2016). Rio de Janeiro: ANS. Recuperado em 29 de maio de 2019, de: http://www.ans.gov.br/perfil-do-setor/dados-e-indicadores-do-setor/dados-do-programa-de-qualificacaode-operadoras

Agência Nacional de Saúde Suplementar (2018a). Anuário 2017: Aspectos econômico-financeiros das operadoras de plano de saúde. Rio de Janeiro: ANS. Recuperado em 14 de novembro de 2019, de: http://www.ans.gov.br/aans/quem-somos/108-materiais-para-pesquisas/2953-anuario-aspectos-economicofinanceiros-das-operadoras-de-plano-de-saude

Agência Nacional de Saúde Suplementar (2018b). Beneficiários. In Caderno de informação da saúde suplementar: beneficiários, operadoras e planos (jun. 2017). Rio de Janeiro: ANS. Recuperado em 16 de março de 2019, de:

http://www.ans.gov.br/images/stories/Materiais para pesquisa/Perfil setor/Caderno informacao saude su plementar/caderno informacao junho 2017.pdf

Agência Nacional de Saúde Suplementar (2018c). Ficha técnica dos indicadores do Programa de Qualificação de Operadoras (ano base 2017). Rio de Janeiro: ANS. Recuperado em 16 de março de 2019, de: http://www.ans.gov.br/perfil-do-setor/dados-e-indicadores-do-setor/dados-do-programa-de-qualificacaode-operadoras

Agência Nacional de Saúde Suplementar (2019a). Anuário 2018: Aspectos econômico-financeiros das operadoras de plano de saúde. Rio de Janeiro: Recuperado em 14 de novembro de 2019, de:

http://www.ans.gov.br/aans/quem-somos/108-materiais-para-pesquisas/2953-anuario-aspectos-economicofinanceiros-das-operadoras-de-plano-de-saude

Agência Nacional de Saúde Suplementar (2019b). Ficha técnica dos indicadores do Programa de Qualificação de Operadoras (ano base 2018). Rio de Janeiro: ANS. Recuperado em 05 de junho de 2019 , de: http://www.ans.gov.br/perfil-do-setor/dados-e-indicadores-do-setor/dados-do-programa-de-qualificacaode-operadoras

Barnes, P. (1987). The analysis and use of financial ratios: a review article. Business Finance and Accounting, 14 (4), 449-461. DOI: http://dx.doi.org/10.1111/j.1468-5957.1987.tb00106.x

Beaver, W. (1966). Financial ratios as predictors of failure. Journal of Accounting Research, 4, 71-111. DOI: http://dx.doi.org/10.2307/2490171

Bhimani, A. \& Langfield-Smith, K. (2007). Structure, formality and the importance of financial and nonfinancial information in strategy development and implementation. Management Accounting Research, 18 (1), 3-31. DOI: http://dx.doi.org/10.1016/j.mar.2006.06.00

Brooks, C. Introductory Econometrics for Finance. 4 ed. Cambridge: Cambridge University Press, 2019. 
Kaplan, R. S. \& Norton, D. P. (1992). The Balanced Scorecard: measures that drive performance. Harvard Business Review, 70 (1), 71-79.

Lei $n^{\circ}$ 9.656, de 3 de junho de 1998 (1998). Dispõe sobre os planos e seguros privados de assistência à saúde. Brasília, DF. Recuperado em 23 de março de 2019, de: http://www.planalto.gov.br/ccivil 03/leis/19656.htm

Lei no 9.961, de 28 de janeiro de 2000 (2000). Dispõe sobre a criação da Agência Nacional de Saúde Suplementar - ANS e dá outras providências. Brasília, DF. Recuperado em 23 de março de 2019, de: https://www2.camara.leg.br/legin/fed/lei/2000/lei-9961-28-janeiro-2000-369733-publicacaooriginal-1-pl.html

Fávero, L. P., Belfiore, P., Silva, F. L. \& Chan, B. L. (2009a). Regressão logística e regressão logística multinomial. In Análise de dados: modelagem multivariada para tomada de decisões (pp. 439-465). Rio de Janeiro, RJ: Elsevier.

Fávero, L. P., Belfiore, P., Silva, F. L. \& Chan, B. L. (2009b). Análise Fatorial. In Análise de dados: modelagem multivariada para tomada de decisões (pp. 439-465). Rio de Janeiro, RJ: Elsevier.

Federação Nacional de Saúde Suplementar (2018). A dimensão social e econômica do setor de saúde suplementar. Recuperado em 08 de março de 2021, de: https://fenasaude.org.br/publicacoes/a-dimensaosocial-e-economica-do-setor-de-saude-suplementar.html

Federação Nacional de Saúde Suplementar (2019). Uma nova saúde suplementar para mais brasileiros. Recuperado em 08 de março de 2021, de: https://fenasaude.org.br/publicacoes/uma-nova-saudesuplementar-para-mais-brasileiros.html

Fernandes, J. L., Cailleau, R. \& Souza, A.A. (2019). Análise de indicadores econômico-financeiros das operadoras de plano de saúde. Anais do XIX USP International in Conference in Accounting. São Paulo, SP, BR.

Guimarães, A. L. de S. \& Alves, W. O (2009). Prevendo a insolvência de operadoras de planos de saúde. Revista de Administração de Empresas - RAE, 4 (40), 459-471. DOI: https://doi.org/10.1590/S0034$\underline{75902009000400009}$

Guzella, M. \& Rodrigues, A. (2015). Avaliação do poder preditivo do desempenho operacional a partir da situação econômico-financeira das distribuidoras brasileiras de energia elétrica. Anais do VI Congresso Nacional de Administração e Contabilidade. Rio de Janeiro, RJ, BR.

Hair Júnior, J. H., Black, W. C., Babin, B. J., Anderson, R. E. \& Tatham, R. L. (2009a). Análise Discriminante Múltipla e Regressão Logística In Análise Multivariada de Dados. (6a ed., pp.221-301) Porto Alegre: Bookman. (Obra original publicada em 2006).

Hair Júnior, J. H., Black, W. C., Babin, B. J., Anderson, R. E. \& Tatham, R. L. (2009b). Análise Fatorial In Análise Multivariada de Dados. (6a ed., pp.100-146) Porto Alegre: Bookman. (Obra original publicada em 2006).

Jesus, L. F., Queiroz, J. M., Macedo, M. A. S., Cruz, C. F. \& Sauerbronn, F. F. (2019). Relação entre indicadores financeiros e não financeiros das operadoras de planos de assistência à saúde. Contabilidade, Gestão e Governança, 22 (3), 316-333. DOI: http://dx.doi.org/10.21714/1984-3925 2019v22n3a1

Kothari, C. R. (2004). Research methodology: methods and techniques (2a ed). New Delhi: New Age International Publishers.

Kudlawicz, C. (2013). Um estudo sobre o impacto no nível de rentabilidade das organizações operadoras de planos de saúde em função do seu perfil. 2013. Dissertação de Mestrado em Ciências Contábeis, Universidade Federal do Paraná, Curitiba, PR, Brasil.

Kudlawicz, C. \& Santos, J. L. (2013). Perfil financeiro das empresas brasileiras operadoras de planos de saúde: um estudo exploratório. Conhecimento Interativo, 7 (1), 30-47.

http://app.fiepr.org.br/revistacientifica/index.php/conhecimentointerativo/article/view/135

Kumar, R. (2011). Research methodology: a step-by-step guide for beginners (3a ed) [S.I.] SAGE. 
Zhen-Jia-Liu, Z. J. (2014). Cross-country study on the determinants of bank financial distress. Revista de Administração de Empresas FGV-EAESP, 55 (5), 593-603. DOI: https://doi.org/10.1590/S0034$\underline{759020150510}$

Matarazzo, D. C. (2010). Análise Financeira de Balanços (7a ed.). São Paulo: Atlas.

Nogueira, C. A. L. (2004). Análise da estrutura econômica do mercado de saúde suplementar: em busca de uma estrutura eficiente de mercado. Dissertação de Mestrado em Saúde Pública, Fundação Oswaldo Cruz, Rio de Janeiro, RJ, Brasil.

Oliveira, D. F. \& Kornis, G. E. M. (2017). A política de qualificação da saúde suplementar no Brasil: Uma revisão crítica do índice de desempenho da saúde suplementar. Physis: Revista de Saúde Coletiva, 27 (2), 207-231. DOI: https://doi.org/10.1590/s0103-73312017000200003

Sancovschi, M., Macedo, M. A. S. \& Silva, J. A. (2014). Análise das intervenções da agência nacional de saúde suplementar (ans) através dos Índices de Desempenho da Saúde Suplementar (IDSS).

Contabilidade, Gestão e Governança, 17 (2), 118-136.

http://www.spell.org.br/documentos/ver/32656/analise-das-intervencoes-da-agencia-nacional-de-saudesuplementar--ans--atraves-dos-indices-de-desempenho-da-saude-suplementar--idss-li/pt-br

Sampieri, R. H.; Collado, C. F. \& Lucio, M. P. B. (2013). Definições dos enfoques quantitativo e qualitativo, suas semelhanças e diferenças. In Metodologia de Pesquisa (5a ed, pp.27-48). Porto Alegre: Penso.

Scalzer, R. S., Rodrigues, A. \& Macedo, M. A. S. (2015). Insolvência empresarial: um estudo sobre as distribuidoras de energia elétrica brasileiras. Revista Contemporânea de Contabilidade, 12 (27), 27-60. DOI: https://doi.org/10.5007/2175-8069.2015v12n27p27

Silva, V. V. \& Loebel, E. (2017). Desempenho econômico-financeiro de operadoras de planos de saúde suplementar. Revista de Gestão em Sistemas de Saúde, 5 (2), 57-70. DOI:

http://dx.doi.org/10.5585/rgss.v5i2.260

Soares, M. A., Thóphilo, C. R. \& Corrar, L. J. (2009). Avaliação de indicadores econômico-financeiro de operadoras de planos de saúde brasileiras: uma aplicação da análise fatorial. Anais do XXXIII Encontro da ANPAD. São Paulo, SP, Brasil.

Veloso, G. G. \& Malik, A. M. (2010). Análise do desempenho econômico-financeiro de empresas de saúde. RAE eletrônica, 9 (1). Xavier, D. O., Souza, A. A. \& Avelar, E. A. (2019). Determinantes do desempenho econômico-financeiro de operadoras de planos de saúde. Revista de Administração Hospitalar e Inovação em Saúde, 16 (1), 48-67. DOI: https://doi.org/10.21450/rahis.v16i1.4947

\section{NOTAS}

\section{AGRADECIMENTOS}

Não se aplica.

\section{CONTRIBUIÇÃO DE AUTORIA}

Concepção e elaboração do manuscrito: T. A. Reis, J. A. V. C. Marques, M. A. S. Macedo

Coleta de dados: T. A. Reis

Análise de dados: T. A. Reis, M. A. S. Macedo

Discussão dos resultados: T. A. Reis

Revisão e aprovação: T. A. Reis, M. A. S. Macedo, J. A. V. C. Marques

\section{CONJUNTO DE DADOS DE PESQUISA}

Todo o conjunto de dados que dá suporte aos resultados deste estudo foi publicado no próprio artigo.

\section{FINANCIAMENTO}

Em conformidade com a Portaria $n^{\circ} 206$, de 4 de setembro de 2018, "o presente trabalho foi realizado com apoio da Coordenação de Aperfeiçoamento de Pessoal de Nível Superior - Brasil (CAPES) - Código de Financiamento 001".

\section{CONSENTIMENTO DE USO DE IMAGEM}

Não se aplica. 


\section{APROVAÇÃO DE COMITÊ DE ÉTICA EM PESQUISA}

Não se aplica.

\section{CONFLITO DE INTERESSES}

Não se aplica.

\section{LICENÇA DE USO}

Os Direitos Autorais para artigos publicados neste periódico são do autor, com direitos de primeira publicação para a Revista. Em virtude de aparecerem nesta Revista de acesso público, os artigos são de uso gratuito, com atribuições próprias, em aplicações educacionais, de exercício profissional e para gestão pública. A Revista adotou a licença Creative Commons Atribuição 4.0 Internacional - CC BY NC ND. Esta licença permite acessar, baixar (download), copiar, imprimir, compartilhar, reutilizar e distribuir os artigos desde que com a citação da fonte, atribuindo os devidos créditos de autoria. Nesses casos, nenhuma permissão é necessária por parte dos autores ou dos editores. Autores têm autorização para assumir contratos adicionais separadamente, para distribuição não-exclusiva da versão do trabalho publicada nesta revista (ex.: publicar em repositório institucional ou um capítulo de livro).

\section{PUBLISHER}

Universidade Federal de Santa Catarina. Curso de Ciências Contábeis e Programa de Pós-graduação em Contabilidade. Publicação no Portal de Periódicos UFSC. As ideias expressadas neste artigo são de responsabilidade de seus autores, não representando, necessariamente, a opinião dos editores ou da universidade.

\section{EDITORES}

Carlos Eduardo Facin Lavarda e Suliani Rover

\section{HISTÓRICO}

Recebido em: 23/09/2020 - Revisado por pares em: 08/03/2021 - Reformulado em: 09/04/2021 Recomendado para publicação em: 07/05/2021 - Publicado em: 30/06/2021

*Preprint do artigo apresentado no Congresso Brasileiro de Custos, 2020. 